\title{
Relação Pensamento-Linguagem e as Distorções Conceituais no Ensino de Biologia
}

\section{The Relation between Thought and Language, and Misunderstandings in the Teaching of Biology}

(iD)

Beatriz Ceschim ${ }^{1}$

Matheus Ganiko-Dutra'

Ana Maria de Andrade Caldeira ${ }^{1}$

1Universidade Estadual Paulista (UNESP), Faculdade de Ciências, Programa de Pós-Graduação em Educação para a Ciência, Bauru, SP, Brasil.

Autora Correspondente: biaceschim@gmail.com

Resumo: O objetivo geral deste trabalho foi investigar as distorções conceituais decorrentes da relação pensamento-linguagem que ocorrem no Ensino de Biologia, identificando as variáveis que possam interferir na articulação didática. Realizou-se um levantamento, por meio de trabalhos, a partir das pesquisas em andamento e publicadas pelo Grupo de Pesquisa em Epistemologia da Biologia (GPEB), da Universidade Estadual Paulista Júlio de Mesquita Filho (UNESP) ao longo da última década, que permitiu sistematizar um conjunto de variáveis identificadas, dificultadoras da articulação didática, epistemológica, linguística e cognitiva na Formação Inicial de Professores em Ciências Biológicas e que resultam na não compreensão da Biologia como ciência e suas inter-relações. Os resultados sugeriram que a polissemia e as figuras de linguagem estimulam o pensamento humano a promover distorções conceituais que se opõem à Epistemologia da Biologia.

Palavras-chave: Ensino de Biologia; Formação inicial do professor; Didática; Epistemologia; Processo cognitivo.

Abstract: The aim of this study was to investigate the misunderstandings produced by the relationship between thought and language in Biology Education, with the identification of variabilities that may interfere with didactic articulation. We have surveyed data from research both in progress and published over the last decade by the Epistemology of Biology Research Group of São Paulo State University (UNESP). This has allowed for the systematization of a set of identified variables, which can pose difficulty to the articulation of didactic, epistemological, cognitive and linguistic processes in the initial training/education of teachers of biological sciences and that may lead to the incomprehension of Biology as a science or its inter-relations. The results suggest that polysemy and figures of speech stimulate human thought to distort concepts that are contrary to Biological Epistemology.

Keywords: Biology teaching; Initial teacher training; Didactics; Epistemology; Cognitive processes.

Recebido em: 22/04/2020

Aprovado em: 07/10/2020 


\title{
Introdução
}

A fragmentação do currículo em cursos de Ciências Biológicas - Bacharelado e Licenciatura - foi amplamente pesquisada pelos participantes do Grupo de Pesquisa em Epistemologia da Biologia (GPEB) (por exemplo, ANDRADE, 2011; BRANDO, 2010). Tais cursos apresentam, em sua maioria, uma organização curricular estanque em que o conjunto de disciplinas específicas são tratadas de forma isolada. Fisher, Wandersee e Moody (2001) já advertiam sobre a dificuldade dos campos conceituais da Ciência e da Educação em Ciência produzirem um currículo articulado voltado para formação integrada. Essa estrutura curricular normalmente propicia poucas possibilidades didáticas capazes de contribuir para que os futuros professores e pesquisadores atinjam uma reorganização epistemológica consistente do conhecimento biológico.

Se o processo de construção de conhecimentos biológicos não ocorre de forma devidamente articulada, os alunos acabam por optar por suas opiniões pessoais, que foram estabelecidas com base em outros domínios do pensar, em vez de recorrerem a conceitos biológicos que estão assentados em construções epistemológicas sólidas, o que resulta em prejuízos para a ação didática. Alguns dos dificultadores são as distorções conceituais produzidas durante a formação inicial do aluno e na sua própria vivência (CALDEIRA, 2009; MARTÍNEZ, 2003).

Uma análise documental das pesquisas já publicadas e que vem sendo produzidas fornecem um banco de dados com um conjunto consistente de distorções conceituais que nos permite categorizá-las e analisá-las. Dessa forma, o presente trabalho buscou identificar, categorizar e exemplificar distorções conceituais no conhecimento biológico que possam ser impeditivos de uma construção epistemológica consistente e de uma ação didática eficaz.

\section{Referencial Teórico}

\begin{abstract}
As palavras e as frases que usamos e a complexa rede de relacionamentos entre seus usos são os óculos através dos quais vemos a nós mesmos e vemos o mundo. [...] Se as lentes estão sujas e obscurecem a visão, se for muito fácil confundir reflexos na lente com coisas vistas, se a curvatura das lentes conduz a certas distorções, então é imperativo prestar atenção aos óculos com os quais vemos o mundo. (HACKER, 2010, p. 27-28).
\end{abstract}

Um dos principais meios pelos quais professores podem acessar os indicadores de aprendizagem dos estudantes são as declarações escritas ou orais, ou seja, a linguagem mediada por palavras. Se a linguagem é uma via que codifica e externaliza o pensamento humano (EVANS; GREEN, 2006), a relação entre linguagem e pensamento se torna central para compreender e alterar o processo de ensino e aprendizagem.

A linguagem nos fornece indicadores detectáveis que permitem entender da natureza, da estrutura e da organização do pensamento, uma vez que o nosso sistema conceitual origina propriedades da linguagem - esta é uma afirmação fundamental que sustenta a Linguística Cognitiva (EVANS; GREEN, 2006). O sistema conceitual, por sua vez, é originado da experiência homem-mundo, que percebe dimensões do mundo exterior, por meio da interação sensorial e sociocultural (EVANS; GREEN, 2006).

É necessário indicar que consideramos aqui o entendimento de "significado da palavra" a partir da perspectiva da Semântica Cognitiva, que defende que, diferente de 
uma definição (visão de dicionário), o significado das palavras é dado por meio de uma visão enciclopédica. A partir desse ponto de vista, admite-se que uma unidade, como uma palavra, não é entendida independentemente/desconectada de um inventário ou repositório de conhecimento enciclopédico vinculado, cuja origem é a interação humana social e física (EVANS; GREEN, 2006; FILLMORE, 2006; LANGACKER, 2006).

A descrição semântica de uma expressão leva, como ponto de partida, uma concepção integrada de complexidade arbitrária e o escopo enciclopédico. Podemos postular hierarquias de complexidade conceitual, nas quais estruturas de um determinado nível emergem de níveis inferiores ${ }^{1}$ (LANGACKER, 2006). Ou seja, para explorar significados, é necessário ir além de uma visão de palavras como entidades autônomas, pois é preciso fazer uma análise completa que envolve uma integração de como a cognição atua na produção e externalização de conceitos rotulados em palavras.

Assim, é importante prezar pela forma como o discurso viabiliza a mediação didática de conteúdos de Ciências da Natureza, haja vista que a relação mundo-percepção-conceitos pode sofrer distorções quando é introduzida exclusivamente pela via da linguagem, ou seja, o estudante pode conceber objetos, processos e estados da natureza de modo equivocado.

O fenômeno da distorção conceitual derivada da aprendizagem mediada pela linguagem tem sido evidenciado nos estudos do Grupo de Pesquisa em Epistemologia da Biologia, especialmente quando se trata de conteúdos que não permitem o uso direto das vias sensoriais do estudante. É o que ocorre em escalas visuais abaixo das microscópicas (como conteúdo de genética molecular) ou o que ocorre em escalas temporais prolongadas que impedem a captura das mudanças dos elementos que compõem um conjunto (como no conteúdo de evolução).

É natural e esperado que ocorra o mal-entendido/distorção na aprendizagem quando o ensino ocorre somente pela via da linguagem: o sistema conceitual humano é sustentado pela percepção e deriva de meios que incluem experiências sensoriais e introspectivas, cujas representações mentais não podem ser codificadas/externalizadas em seu todo somente por palavras. Ou seja, a linguagem é menos rica em detalhes que a experiência perceptiva e menos rica em detalhes que a representação mental dessa experiência (EVANS; GREEN, 2006). Assim, pode-se afirmar que, mediada por um sistema simbólico, a linguagem falada ou escrita sofre perda da riqueza da dimensão multimodal da representação conceitual, sendo, portanto, uma via limitada e limitante para expressar o pensamento (EVANS; GREEN, 2006). Basta lembrar de uma situação corriqueira na qual ocorre a frustração de um impedimento para colocar uma ideia em palavras e a razão para tal é que há um número finito de palavras com seus respectivos significados convencionais. Pensando nas limitações que a comunicação mediada pela linguagem humana representa para o processo de aprendizagem conforme nossos dados do Grupo de Pesquisa em Epistemologia da Biologia apontaram ao longo dos anos, a metodologia do presente trabalho foi desenvolvida.

\section{Metodologia}

Para categorizar o conjunto de distorções conceituais de que dispomos, optamos por sistematizar concepções dos estudantes por meio da organização de um quadro (Quadro 1)

\footnotetext{
${ }^{1}$ A noção hipotenusa é prontamente caracterizada, dada a concepção prévia de um triângulo retângulo, mas
} incoerente sem ele. $\mathrm{O}$ triângulo retângulo, portanto, funciona como o domínio cognitivo da hipotenusa. 
que apresenta critérios para qualificar distorções conceituais em Biologia organizado em três eixos, a saber: linguagem, natureza do pensamento humano e uso do conhecimento biológico. A escolha dos itens refere-se à (a) codificação do conceito, (b) seu significado e (c) seu uso, tal como são utilizados na Linguística Cognitiva (EVANS; GREEN, 2006).

Quadro 1 - Critérios para qualificar distorções conceituais em Biologia

\begin{tabular}{|c|c|c|}
\hline 1. Linguagem & $\begin{array}{l}\text { 2. Natureza do pensamento } \\
\text { humano }\end{array}$ & $\begin{array}{l}\text { 3. Aplicação do conhecimento } \\
\text { biológico }\end{array}$ \\
\hline $\begin{array}{l}\text { 1.1 Polissemia } \\
\text { 1.1.1 Polissemia: cotidiano versus científico } \\
\text { 1.1.1 Polissemia: científico versus científico } \\
\text { 1.2 Metáfora } \\
\text { 1.3 Metonímia } \\
\text { 1.4 Antítese } \\
\text { 1.5 Personificação }\end{array}$ & $\begin{array}{l}\text { 2.1 Causação linear (fenômeno) } \\
\text { 2.2 Dicotomização (objeto) } \\
\text { 2.3 Cartesianismo } \\
\text { 2.4 Teleologia } \\
\text { 2.4.1 Reação com finalidade } \\
\text { 2.4.2 Natureza onisciente: antevisão } \\
\text { 2.4.3 Propósito ou progresso }\end{array}$ & $\begin{array}{l}\text { 3.1 Desvinculação da representação com } \\
\text { o fenômeno em si } \\
\text { 3.2 Segmentação conceitual } \\
\text { 3.3 Desvio de nível hierárquico de } \\
\text { organização biológica }\end{array}$ \\
\hline
\end{tabular}

Fonte: elaborado pelos autores.

Na primeira parte do quadro, tratamos especificamente da categorização da natureza das distorções conceituais referentes somente à linguagem: no que diz respeito à polissemia no discurso didático, bem como no discurso que relaciona a cultura escolar, a pluralidade cultural, e a relação conotativo-denotativo (figuras de linguagem). Na segunda parte do quadro, a categorização das distorções conceituais é referente à natureza do pensamento humano, principalmente no que tange ao modo de conceber a si próprio e de generalizar como o ser humano funciona para a compreensão de outros processos do mundo. Na terceira parte do quadro, os critérios para categorizar concepções são mais abrangentes e podem facilmente ser combinadas com critérios da primeira e da segunda parte, inclusive funcionando como consequências delas. Trata-se de itens que são específicos da Epistemologia da Biologia, pois são modos particulares de aplicar o pensamento biológico. Dessa forma, a construção categorial será tomada como base de análise dos dados acrescidos dos exemplos em que foram identificadas as distorções conceituais.

\section{Descrição e Análise dos Dados}

\section{Linguagem}

Uma das finalidades da linguagem é a expressão de pensamentos e ideias, pois ela codifica e externaliza pensamentos. $O$ modo pelo qual a linguagem viabiliza a externalização é utilizando símbolos, como: palavras inteiras, partes de palavras ou sequências de palavras. Os símbolos estão associados a significados que são conteúdos semânticos convencionais. O significado está ligado a uma representação mental, denominada conceito; e as palavras rotulam conceitos. Os conceitos, por sua vez, são originados das percepções. As informações obtidas pelas vias sensoriais são integradas em uma imagem mental coerente e bem definida e os significados rotulados pelos símbolos linguísticos evocam essa representação mental da realidade (EVANS; GREEN, 2006).

Além da finalidade de expressar pensamentos e ideias, a linguagem também tem a função interativa, que consiste em tornar reconhecíveis e acessíveis aos demais sujeitos de uma comunidade os significados que compõem a linguagem. Na transmissão das ideias, deverá ocorrer então a comunicação, ou seja, o emissor transmite a informação e ocorre a decodificação pelo receptor (EVANS; GREEN, 2006). 
Todavia, nem sempre que ocorre o processo de transmissão de uma informação, ocorre comunicação. Esse risco é muito caro para um professor, pois a causa para o impedimento da efetivação da comunicação pode ser o fenômeno do ruído de comunicação (no qual a mensagem que é interpretada pelo receptor é alterada) e a aprendizagem pode ser prejudicada. É o que ocorre, por exemplo, nos casos de polissemia.

\section{Polissemia}

No que tange à polissemia, as palavras possuem uma gama considerável de sentidos inter-relacionados, que definem o alcance de seu uso sancionado convencionalmente. A polissemia é o fenômeno no qual uma única unidade linguística exibe múltiplos significados distintos, que podem estar relacionados (EVANS; GREEN, 2006).

Para tratar de polissemia, podemos utilizar a teorização da semântica de frames de Fillmore (2006). Um frame, ou quadro, para o autor, significa um sistema de categorias estruturadas em acordo com algum contexto motivador. O frame se constitui de modo sistematizado, como se fosse uma cena que organiza experiências passadas e que se apresenta ao ser lembrado quando a palavra o evoca. A polissemia pode surgir quando frames alternativos são evocados a partir de uma mesma palavra (FILLMORE, 2006). Sob esta ótica, dois tipos de polissemia que causam distorções conceituais serão explorados a seguir.

\section{Polissemia: cotidiano versus científico}

Algumas palavras podem ter um uso geral na vida cotidiana, mas passam a ter um uso separado na linguagem técnica. Nestes casos, os frames não estão relacionados e a percepção não auxilia o processo da compreensão, impedindo que as noções se encaixem (FILLMORE, 2006). A disparidade de frames citada pode causar ruídos de comunicação, um fenômeno que pode ser entendido como uma falha de comunicação por conflito de frame (FILLMORE, 2006).

De acordo com seu conhecimento enciclopédico pessoal, o estudante poderá interpretar um item léxico de formas diferentes daquelas que o professor espera, devido às experiências culturais em geral que o estudante possui. O fenômeno dos "modos de ver" (ways of seeing) origina-se do fato de cada indivíduo ter experiências diferentes, que implica em representações mentais individuais autênticas. Isso cria um repertório ou conhecimento enciclopédico que pode influenciar como as palavras são interpretadas (CRUSE, 2011).

No ensino, há palavras que precisam adquirir frames alternativos (diferenciação do significado) para que ocorra a alfabetização científica. Alguns exemplos incluem: 'energia', 'força', 'peso', 'clima', 'calor' e 'fruto'. Embora a escola ensine (verbalmente) o conceito científico que corresponde ao significado de dicionário de uma palavra polissêmica, nem sempre ocorre a aprendizagem do frame referente à palavra em seu sentido científico. $A$ situação na qual o estudante sofre por uma falha de comunicação causada por conflito de frame será aqui denominada como Distorção conceitual por polissemia.

No Grupo de Pesquisa em Epistemologia da Biologia, constatamos a Distorção conceitual por polissemia e citaremos um exemplo. O fenômeno ocorreu porque as noções não se encaixam, visto que os frames do uso cotidiano e do uso científico da palavra não têm relação. O item léxico a ser considerado é: 'evolução'. O uso científico que a Biologia 
faz desse termo transformou os frames de modo que os significados cotidiano-científico tornaram-se distantes.

A evolução biológica, por exemplo, tradicionalmente entendida como descendência com modificação se distancia muito da conotação de melhora/progresso do uso cotidiano. A importância de discutir o fenômeno da Distorção conceitual por polissemia proposta aqui é o risco de que, ao aprender o conteúdo científico, o estudante possa 'emprestar' atributos incompatíveis do frame alternativo. Antes de colocar em outras palavras para tornar mais claro, vamos ao exemplo. No GPEB, os professores de Biologia em formação foram convidados a enunciar como entendiam o conceito de evolução biológica oralmente (ver mais em CESCHIM, 2017). Algumas falas obtidas foram: [A1]: sempre que se fala em evolução, me vem à cabeça melhoramento. [A2]: acho que vai passando por toda a complexidade, desde os mais simples até os mais complexos. [conotação de progresso]

Nestes casos, o processo de 'emprestar' atributos do frame cotidiano da palavra evolução para o uso científico da palavra causa distorções, pois trata-se de características que são incompatíveis com o conhecimento biológico e que podem ter sido originadas pela própria palavra que rotula o conceito, em associação (ou não) com outras causas.

Não é somente do contexto cotidiano que frames alternativos podem ser desviados com o efeito de distorcer compreensões científicas: o próprio conhecimento científico é polissêmico ao utilizar-se de um mesmo item léxico em diferentes contextos. As implicações para o ensino serão discutidas na próxima seção.

\section{Polissemia: científico versus científico}

Quando a ciência faz uso de uma mesma palavra para se referir a diferentes elementos, o discurso didático pode fazer uma simples reprodução da polissemia sem qualquer diferenciação dos usos variados que aquele item léxico pode adquirir. A diferenciação, neste caso, é dada somente pelo contexto, mas somente do aprendiz mais experiente se esperaria a capacidade de fazer a diferenciação por meio do contexto, o que significa esperar que muitos outros aprendizes estariam sofrendo processos de confusão.

Podemos utilizar aqui o exemplo da palavra "adaptação" em Biologia. Lucas (1971) indica pelo menos três significados que ela tem no contexto biológico: (a) adaptação evolutiva; (b) adaptação fisiológica; e, (c) adaptação sensorial. A adaptação evolutiva é o (a1) processo pelo qual se adquire uma característica a qual torna-o melhor ajustado a viver ou se reproduzir em seu ambiente; também pode ser qualquer, (a2) característica de organismos vivos que tenham aumentado suas chances de sobrevivência e de deixar descendentes em comparação com outros organismos desprovidos dessa característica. Em outras palavras, seria uma característica fixada em uma população por seleção natural. A (b) adaptação fisiológica consiste em uma mudança em um organismo que resulta de uma exposição a certas condições ambientais, que faz com que ele reaja de forma diferente às condições. Por fim, a (c) adaptação sensorial é uma mudança na excitabilidade de um órgão sensorial como resultado de uma contínua estimulação, de modo que um maior estímulo começa a ser necessário para produzir a mesma atividade.

Ontologicamente, podemos apontar que a palavra adaptação cumpre o papel de processo ( $\mathrm{a} 1, \mathrm{~b}$ e c), mas também pode cumprir o papel de objeto (a2). Assim, o termo "adaptação", além da conotação cotidiana, tem polissemia científica interna que garante heterogeneidade de frames e uma complexidade que normalmente não é sinalizada para 
os estudantes. Ainda que seja feita a diferenciação entre adaptação fisiológica e evolutiva, dentro da conotação evolutiva ainda há dois subtipos, como vimos. Para exemplificar a importância dessa Distorção conceitual por polissemia, segue um exemplo do GPEB.

Solicitamos a um grupo de professores de Biologia em formação a justificativa da diferença da velocidade de ação do veneno de serpentes filogeneticamente relacionadas, mas que viviam em ambientes diferentes (jararaca ilhoa da Ilha de Queimada Grande, onde somente há aves como fonte de alimento; e jararaca do continente, onde há alimentos disponíveis no solo). Algumas das respostas obtidas foram (ver mais em CESCHIM, 2017):

A1: a jararaca da ilha se adaptou ao ambiente que está vivendo. Como sua alimentação é escassa e depende de aves, que são animais que voam e são rápidos, precisou-se do veneno com rápida ação para que elas possam sobreviver.

A2: a jararaca da ilha, devido ao seu habitat e seu tipo de alimentação, se adaptou, desenvolveu um veneno mais potente para conseguir se alimentar de aves, o que não acontece com as jararacas de fora da ilha.

A adaptação fisiológica tem um estado final (télos) que confere um status teleológico aceitável para uma frase, uma vez que possui um caráter funcional e não evolutivo. Porém, é possível notar que em ambas as respostas, os estudantes desviaram-se uma vez que se tratava de uma adaptação evolutiva, assim, se equivocaram, cruzando frames que eram da adaptação fisiológica, introduzindo-os para dar significado à adaptação evolutiva.

Por exemplo, na adaptação fisiológica, a homeostase é o estado final no qual os processos fisiológicos culminam. Há normalmente um estímulo inicial que faz desencadear a resposta adaptativa fisiológica e ela ocorre dentro de um ciclo de vida. São diferenças importantes para a adaptação evolutiva, que não tem um estado final, que seria um parâmetro mais ou menos estável no qual o processo evolutivo deve se conduzir. Além disso, não há um estímulo inicial que desencadeia o processo de produção de adaptações, pois as adaptações dependem da inovação da forma (contingente) e da fixação populacional (seleção natural ou outras contingências); e a adaptação evolutiva ocorre ao longo do tempo filogenético e não ontogenético. O verbo 'adaptar' que representa o processo de adaptação causa esse tipo de confusão, representando uma das Distorções conceituais por polissemia referentes ao termo.

Deste modo, pode-se dizer que é preciso diferenciar detalhadamente os frames possíveis de cada um dos usos da palavra adaptação dentro da Biologia para que os estudantes não extraiam significados equivocados acerca da evolução biológica. Também em outros exemplos, a categorização minuciosa, com distinções evidentes postas em palavras pode ser um caminho inicial para sinalizar a polissemia que está ocorrendo em diferentes casos, pois, como pontua Vygotsky (2001), a tomada de consciência é o processo de colocar em palavras.

\section{Metáfora}

A metáfora é o fenômeno no qual um domínio conceitual é sistematicamente estruturado em termos de outro, ou seja, $X$ é entendido em termos de $Y$ (EVANS; GREEN, 2006). O domínio que está sendo descrito é o domínio alvo, ou X, e o domínio em termos do qual o alvo é descrito é a fonte, ou Y.

Metáforas conceituais são unidirecionais porque os domínios de que são fontes não podem ser entendidos com base nos domínios alvo, isto porque a estruturação metafórica é 
parcial, não total. Se fosse total, um conceito seria o outro, e não entendido em termos de outro. Assim, parte de um conceito metafórico não se encaixa e não corresponde (LAKOFF; JOHNSON, 2008). Utilizando a terminologia de Lakoff e Johnson (2008), o link metafórico que une dois domínios consiste em várias correspondências ou mapeamentos (mappings) distintos. Alguns aspectos do domínio alvo e do domínio fonte representam correspondência, outros não. Dessa distinção que se faz entre os aspectos que correspondem e os que não, emerge a classificação dos processos de ocultar (hiding) e destacar (highlighting).

Fazendo uso dos termos 'ocultar' e 'destacar', gostaríamos de apontar que, embora possamos dizer que a metáfora seja uma característica central e inerente da linguagem humana, no Ensino de Biologia, esse recurso do pensamento e da linguagem tem sido a origem do que vamos denominar Distorção conceitual por metáfora. Os estudantes frequentemente 'destacam' aspectos do domínio fonte que não são correspondentes com o domínio alvo e produzem conclusões próprias equivocadas.

Examinemos o caso das micorrizas e a teoria dos mercados biológicos (biological markets) como um exemplo da forma que o pensamento metafórico estrutura o conhecimento biológico e pode promover Distorção conceitual por metáfora. Micorrizas são relações simbióticas mutualísticas estabelecidas entre fungos e raízes de plantas. As plantas fornecem fotoassimilados em troca de nutrientes, como nitrogênio e fósforo, que recebem dos fungos, além de proteção contra outros fungos patogênicos e nematódeos (EVERT; EICHHORN, 2014). Em termos da estrutura da metáfora, as micorrizas são o domínio alvo, ou seja, aquele a ser conceituado por meio de outro.

Uma metáfora utilizada no Ensino de Biologia é a de que energia é dinheiro. Tal semelhança entre as relações estabelecidas entre os humanos e as relações estabelecidas entre os demais seres vivos levou à formulação da teoria dos mercados biológicos. Neste modelo, os mutualismos são entendidos por meio de um mercado de trabalho (domínio fonte): dois tipos de comerciantes trocam produtos por benefício mútuo. Nöe e Hammerstein (1995) definiram as características do mercado que se aplicam aos mutualismos: (a) há competição entre comerciantes da mesma classe por disputa da obtenção do melhor produto pela oferta de menor valor; (b) há preferência por parceiros que oferecem o melhor valor; e (c) os conflitos se estabelecem a partir da mudança do valor dos produtos. Os autores ressaltam também, termos que são jargões da economia que são aplicadas a esta teoria, como market selection, commodity e trader class. Estes são os aspectos destacados do domínio fonte.

A teoria dos mercados biológicos, evidencia que plantas fornecem mais carboidratos para fungos parceiros que oferecem mais fósforo, e vice-versa (WYATT et al., 2014). Assim como no mercado de trabalho, as relações não são isoladas: cada parceiro possui vários outros parceiros de comércio. Dessa forma, uma planta estabelece relações com vários fungos, que por sua vez, interagem com diversas plantas. Além disso, os indivíduos interagem obedecendo a uma discriminação proporcional linear. A proporção de carbono fornecida a um fungo por uma raiz, é proporcional à porcentagem de fósforo recebida.

Entretanto, apesar de ser possível conceber as relações mutualísticas das micorrizas por meio dos jargões da economia, alguns termos podem se ocultar, ou serem mal compreendidos, o que pode promover Distorção conceitual por metáfora. As transações financeiras estabelecidas por seres humanos são intencionais, enquanto as micorrizas são interpretadas por modelos experimentais como um produto da seleção natural, uma 
interação estável ao longo do tempo evolutivo, estabelecida ao longo de milhares de anos a partir de interações múltiplas e simultâneas, que favoreceu o aumento de fitness de indivíduos que se especializavam em obter um recurso a partir do comércio (KIERS et al., 2016).

Outro exemplo de Distorção conceitual por metáfora é proveniente do conteúdo de genética mendeliana, no que diz respeito ao conteúdo de dominância/recessividade. Considere a frase:

[...] ele [Mendel] deduziu que as plantas altas da geração F1 possuíam um fator que determinava que seriam baixas, mas que de alguma maneira isso foi inibido pela expressão de outro fator para plantas altas. $O$ fator inibido foi chamado recessivo, e o fator expresso foi chamado dominante. (OGO; GODOY, 2016, p.16, grifo nosso).

Sendo este trecho uma parte de um discurso didático, é razoável que estudantes entendam que o fator para plantas baixas que "foi inibido pela expressão de outro fator" ocorreu por meio do seguinte processo: o fator dominante (alto) inibe diretamente o fator recessivo (baixa). É a linguagem que sugere essa relação ao fazer uso do termo 'pela'. O estudante poderá imaginar dois cromossomos homólogos, cada um com seu lócus gênico e ao substituir posteriormente o termo 'fator' pelo termo 'alelo', poderá concluir (equivocadamente) que um alelo inibe a ação do outro. Além disso, o próprio processo de 'dominação' implica automaticamente em imaginar uma dimensão dominante e outra dimensão dominada pelo dominante. Ora, se um alelo é dominante, o outro deveria ser dominado por ele, não? Não, pois fisiologicamente, não são os alelos que interagem entre si, mas sim os produtos biológicos sintetizados (como polipeptídios) a partir da sequência de bases nitrogenadas contidas nesses alelos.

Quando Mendel (2008) cunhou os termos, fez apontamentos suficientes para que fosse possível identificar que a dominância e a recessividade eram adjetivos fenomenológicos e não fisiológicos:

O caráter híbrido se assemelha ao de uma das formas parentais tão intimamente que a outra escapa completamente da observação ou não pode ser detectada com clareza. [...]. Esses caracteres do híbrido serão denominados 'dominantes' e aqueles que se tornam latentes no processo serão denominados 'recessivos'. A expressão 'recessivo' foi escolhida porque os caracteres assim designados se retiram ou desaparecem completamente nos híbridos, mas reaparecem inalterados em sua descendência [...] (MENDEL, 2008, p. 15, tradução nossa).

Porém, como discute-se em Ceschim e Caldeira (2020a), a linguagem metafórica introduzida por Mendel causa distorções conceituais, uma vez que se tornou mal empregada em frases, como visto no exemplo do livro didático, estimulando os estudantes a entenderem que um alelo se comportaria como dominante, de modo a inibir diretamente a ação de outro alelo que se comportaria como recessivo.

Os exemplos da micorriza e da dominância evidenciam a possibilidade de distorções conceituais ao utilizar metáforas no Ensino de Biologia. Em ambos os exemplos, há incompatibilidades entre o conceito alvo e o conceito fonte que, se não forem explicitadas, impedem que o estudante alcance uma construção conceitual adequada com relação à aprendizagem científica. Portanto, na ação didática, faz-se necessário que os conhecimentos científicos que são emitidos por meio de uma linguagem ou um pensamento metafórico sejam identificados e explicitados como tal, para que não se tomem como 
denotativos os significados conotativos que sejam atributos apenas do domínio fonte incompatíveis com o domínio alvo.

\section{Metonímia}

A metonímia permite a conceituação de um termo a partir da relação que ele estabelece com outro: trata-se de uma questão de representação (LAKOFF; JOHNSON, 2008). Entendida como "a parte pelo todo", no discurso biológico, é comum utilizarmos um indivíduo (parte) para nos referirmos a um táxon (espécie, gênero, família, ordem, classe, filo, reino) ou a um nível de organização superior (população, comunidade, ecossistema, biosfera).

É importante notar que a parte escolhida para a representação do todo, evidencia um aspecto específico dessa relação. Assim como a metáfora, metonímia não é uma simples relação da forma como nos comunicamos, mas uma estrutura do nosso pensamento que está ancorada em nossas experiências (LAKOFF, JOHNSON, 2008).

Lakoff e Johnson (2008) apresentam uma organização sistematizada de exemplos de metonímias presentes na cultura ocidental: parte pelo todo, produtor pelo produto e objeto usado pelo usuário, por exemplo. Dentro desta proposta, tendo em vista o caráter hierárquico da Biologia, nós caracterizamos aqui a metonímia do (i) indivíduo pelo táxon, e do (ii) organismo pelo nível superior de organização.

A metonímia está estruturada por meio de hipônimos e hiperônimos. Os hipônimos são palavras que indicam substantivos hierarquicamente específicos (subordinados), enquanto hiperônimos são palavras que indicam substantivos hierarquicamente abrangentes (superordenados) (CRUSE, 2002). Desta forma, na metonímia (i), a hierarquia em questão é a taxonômica, que varia de espécie até reino/domínio. Nesta hierarquia, reino é um hiperônimo para filos, enquanto este, por sua vez, é um hiperônimo para classes, e assim por diante. Já o termo família, por exemplo, é um hipônimo para ordem. Na metonímia (ii), a hierarquia estrutural estabelece-se a partir do critério tamanho, organizada em níveis que variam de átomo até a biosfera. Neste sentido, comunidade é um hiperônimo de população, assim como organismo é um hipônimo de população, por exemplo. Estas explicações encontramse sintetizadas na Figura 1.

Figura 1 - Representação das hierarquias biológicas

\begin{tabular}{|c|}
\hline REINO/DOMÍNIO \\
\hline \hline FILO \\
\hline \hline CLASSE \\
\hline \hline ORDEM \\
\hline \hline FAMÍLIA \\
\hline \hline GÊNERO \\
\hline ESPÉCIE \\
\hline
\end{tabular}

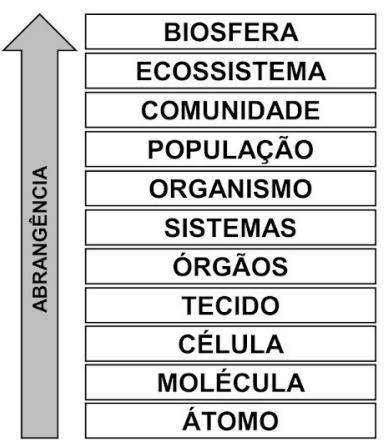

Nota: Os termos mais superiores são termos mais abrangentes, enquanto os mais inferiores são mais específicos, conforme indica o sentido da seta. Analisados par a par, o termo superior é hiperônimo do termo logo abaixo, assim o como o termo inferior é hipônimo do termo logo acima. Os termos da esquerda representam a hierarquia taxonômica referentes à metonímia (i), enquanto os termos da direita representam a hierarquia estrutural em níveis de organização, referentes à metonímia (ii). 
Em relação à metonímia (i) indivíduo pelo táxon, é comum utilizarmos o nome popular de uma espécie para nos referirmos ao táxon, como por exemplo, enunciarmos "a cobra perdeu as patas", quando dizemos respeito a um conjunto muito maior de organismos que apenas um único indivíduo de cobra. Ao utilizarmos a metonímia, neste caso, perdemos a precisão de qual nível taxonômico estamos fazendo referência. São cobras do cerrado? Da América do Sul? Apenas cobras da espécie Boa constrictor? Ou todos indivíduos de Ophidia?

Em determinados contextos, este uso pode não ser problemático, entretanto, enquanto professores, podemos reproduzir uma negligência a respeito da diversidade existente. Quando um professor diz "a cobra", pode ficar subentendido que existe apenas uma única espécie de cobra, sendo que todas seriam iguais. Este obstáculo poderia ser resolvido por meio da limitação da ocorrência dos indivíduos espacial ou taxonomicamente: "a população de indivíduos de Boa constrictor do Brasil" ou "os indivíduos pertencentes a Ophidia".

O uso da metonímia (ii) organismo pelo nível superior de organização mescla níveis biológicos hierárquicos e pode acarretar distorções conceituais porque esconde/anula as propriedades emergentes. Não se trata apenas de uma diferença quantitativa, ou seja, o nível superior, seja ele uma população ou uma comunidade, não constitui um mero agrupamento de indivíduos. A partir de um nível hierárquico superior ao organismo, emergem propriedades que não estavam presentes no nível inferior.

No Ensino de Evolução, as possibilidades de Distorção conceitual por metonímia são comuns. Em nível individual, a dimensão temporal se dá por meio de modificações no desenvolvimento (tempo ontogenético), enquanto na população, além desta propriedade, existe a dimensão de tempo que atravessa gerações (tempo evolutivo). Esta figura de linguagem impede a localização do fenômeno no período de tempo ontogenético ou evolutivo. Quando um professor diz que "o angico desenvolveu um súber espesso", o estudante pode não conseguir situar o fenômeno no tempo evolutivo, isto é, se o surgimento do súber espesso no angico (Anadenanthera peregrina) acontece ao longo do desenvolvimento de cada indivíduo desta espécie, ou se o surgimento aconteceu ao longo das gerações, ou seja, se essa caraterística surgiu em uma geração $\mathrm{F} 1$ a partir de um ancestral da geração parental em que não estava presente esta característica. Além da metonímia, neste caso, a palavra 'desenvolveu' também é problemática porque remete diretamente ao desenvolvimento, sugerindo que a mudança se dá no tempo de vida ontogenético.

Portanto, tendo em vista as distorções conceituais promovidas pela falta de precisão na limitação do táxon ou nível de organização a que se está referindo, bem como da incapacidade de localização temporal do fenômeno, a metonímia é uma figura de linguagem a ser evitada no Ensino de Biologia. Entendida como um 'atalho' linguístico que pode ter consequências para a compreensão dos estudantes, é recomendável que o discurso docente não empregue a metonímia, pois nem sempre os estudantes identificam a relação de representação existente. Ao invés disso, recomenda-se aos docentes especificar o nível taxonômico ou nível hierárquico no tempo e/ou no espaço para tornar precisa a identificação das condições nas quais ocorre um dado fenômeno biológico.

\section{Antítese}

Caracterizada por oposição ou contrariedade semântica, a antítese pode se manifestar na linguagem de modo subconsciente por meio de circunstâncias nas quais 
a intuição conduz o uso da linguagem (KAŁUŻA,1984), pois pensar de forma binária ou pensar por oposições é uma tendência natural da mente humana. A maneira mais fácil de classificar informações complexas é reunindo-as em dois agrupamentos (gostar e não gostar / meu e seu / lobo e cordeiro), assim, as dicotomias prontamente se configuram como os polos negativo e positivo (ELBOW, 1993). Pode ser a própria estrutura de nossos corpos e de elementos do mundo a nossa volta que nos influenciam a conceber elementos em oposições binárias (LAKOFF; JOHNSON, 2008), assim, o sistema perceptivo parece preferir o pensamento dicotômico pois ele oferece menor resistência, no sentido de ser o mais espontâneo (ELBOW, 1993).

No GPEB, constatamos o que pode ser chamado de Distorção conceitual por antítese. Os professores de Biologia em formação categorizaram variáveis biológicas em dois grupos com características opostas. Uma distorção conceitual importante constatada foi aquela na qual os participantes indicaram que os organismos de uma população são divididos em: adaptados e não-adaptados. Em uma população, organismos exibem variabilidade que não se restringe a apenas dois subtipos. Outro problema é situar o lócus da adaptação no organismo, quando a adaptação deve ser localizada em um caráter (CAPONI, 2012) ou em uma comparação entre um organismo e outro (LUCAS, 1971). O excerto a seguir contém duas ocorrências de pensamento binário (ver mais em CESCHIM, 2017):

\section{A1: Aparece uma coisa mais nova e substitui a outra. Tudo bem se ela for melhor, substitui a outra. \\ Pesquisador(a): Mas, como uma função nova substitui a outra? Por quê? \\ A2: Tem um adaptado e um não adaptado, é outra função, que não morreria quem está adaptado.}

Para discutir narrativas seletivas, os estudantes também apontam somente dois fenótipos diferentes representando a variabilidade sobre a qual atuará a seleção natural (CESCHIM, 2017). O enfrentamento dessa distorção requer busca de novos exemplos na literatura, pois é comum encontrar somente exemplos dicotômicos em materiais didáticos. O ideal seria indicar exemplos concretos de gradientes de variabilidade para aumentar o repertório dos estudantes.

\section{Personificação}

A partir do uso automático de metáforas, palavras e estruturas frasais são estruturadas por meio da substituição de fatores causais mecânicos e abstratos por agentes volitivos, assim, o sujeito da frase passa a ter uma natureza intencional (EVANS; GREEN, 2006). Normalmente, no contexto cotidiano, o 'desvio' ocorre apenas em nível da convenção do sistema de linguagem, porque é possível reconhecer de modo espontâneo o caráter metafórico da transferência de fator causal. Considere os exemplos: "O trânsito me atrasou" ou "aquela grama molhada salvou o jogo". Não se espera que o interlocutor imagine que o trânsito ou a grama sejam agentes volitivos que tenham planejado atrasar alguém ou salvar um jogo.

Porém, no contexto didático, o 'desvio' que ocorre ao nível da linguagem, pode ser transmitido também para o nível do pensamento. Ou seja, o interlocutor (o estudante) pode concluir que há, sim, agentes volitivos, intenções e propósitos nas palavras e frases, o que vamos denominar aqui como Distorção conceitual por personificação. Na Biologia, 
existe, por exemplo, uma ampla utilização metafórica do termo 'para' em frases, tornandoas teleológicas. Veja alguns exemplos de livros didáticos:

Exemplo 1: O deslocamento por jatopropulsão é o principal meio de locomoção
das lulas. Já os polvos o utilizam apenas em certas ocasiões, como para fugir de um
predador [...] (LOPES; ROSSO, 2016, p. 192).
Exemplo 2: [...] do papo, o alimento passa para o estômago, modificado em
proventrículo e moela. No proventrículo, há liberação de enzimas digestivas e, em
seguida, o alimento é conduzido para a moela, órgão muito musculoso onde ocorre
a trituração. [...] (LOPES; ROSSO, 2016, p. 267).

O exemplo dois não tem caráter teleológico no uso da palavra 'para', mas o primeiro, sim. Para auxiliar a identificação da teleologia, podemos utilizar como critério: (a) se é possível substituir por "com destino $a$ " se trata apenas de uma preposição referente a localizações; (b) se é possível substituir por "com a finalidade de" (in order to) se trata de um propósito/ função (teleológico), ainda que não haja intencionalidade literal. Considere a frase: "Eu vou para a escola para estudar". O primeiro 'para' se encaixa no caso (a) e o segundo se encaixa na descrição (b).

Metaforicamente, é aceitável no discurso científico dizer que os polvos utilizam jatopropulsão para [com a finalidade de] fugir de um predador. Mas esse tipo de uso na Biologia funcional é transferido também para a Biologia evolutiva, gerando frases/ pensamentos tais como esses obtidos no GPEB (ver mais em CESCHIM, 2017): A1: "O antibiótico vai agir em algum ponto da bactéria [...], mas elas se proliferam tão rápido que acho que aquelas gerações conseguem ir criando uma autodefesa. Elas conseguem criar mecanismos de defesa para inibir o uso daquele antibiótico muito rápido."

\section{Natureza do pensamento humano}

Alguns aspectos epistemológicos da Biologia, e consequentemente o conhecimento biológico, podem ter a aprendizagem dificultada pela própria cognição humana que tem características que espontaneamente diferem da natureza epistemológica biológica.

A Biologia é uma ciência complexa, sistêmica, com propriedades emergentes, com sistemas hierárquicos e contingente (COOPER, 2016; MAYR, 2005). Tais características lhe conferem um nível de dificuldade considerável quando se trata do grau de abstração necessário para compreensão conceitual. Sendo assim, é possível que a simplificação se torne uma tendência (equivocada) no pensamento espontâneo. Trataremos primeiro de tais simplificações e em seguida do pensamento teleológico. Ambos serão abordados como tendências espontâneas da cognição humana que dificultam a aprendizagem da Biologia.

\section{Causação linear (fenômeno)}

O conhecimento biológico está organizado em níveis hierárquicos (átomos-biosfera), ou seja, em átomos, moléculas, células, tecidos, órgãos, sistemas, organismos, populações, comunidades, ecossistemas e biosfera. Cada nível não é a mera soma de suas partes, uma vez que em um nível superior, emergem características que não estavam presentes em um nível inferior. A estes efeitos, denominamos propriedades emergentes. Estas propriedades são multifatoriais e descentralizadas: a partir de um conjunto de interações contingentes e 
simultâneas entre os elementos que existem em um nível hierárquico, emerge um padrão organizado em um nível superior (COOPER, 2016).

Por meio das discussões do GPEB, identificamos que os estudantes têm dificuldade em atribuir relações causais múltiplas para contingências, ou seja, um processo que ocorreu, mas poderia não ter ocorrido (probabilístico). Esta característica atribuição causal linear do pensamento humano constitui um obstáculo a ser superado para a aprendizagem de fenômenos biológicos, que são emergentes, como a produção de fenótipos, conforme será discutido a seguir.

A visão genecêntrica da Biologia foi constatada em concepções de professores em formação por Meglhioratti (2009), Andrade (2011) e por Justina (2011) no GPEB. Sob a perspectiva genecêntrica, o gene é entendido como o fator determinante do fenótipo dos organismos, como se pode notar nas falas de professores de Biologia em formação que foram sujeitos de pesquisa no grupo (ver mais em MEGLHIORATTI, 2009): A1: "A presença de informações genéticas conduz as características básicas do indivíduo." E A2: "O DNA é o responsável por manter essa individualidade dos seres vivos."

Embora o DNA seja um componente importante a ser levado em consideração na constituição fenotípica, não é o único. Os produtos da síntese proteica a partir dessa molécula irão interagir com os estímulos do ambiente interno e externo do organismo, sendo modificados ao longo do desenvolvimento e promovendo o aumento ou inibição da expressão de determinadas sequências. Além disso, o fenótipo também é um resultado da cultura, do comportamento aprendido e de heranças ecológicas (confira discussão acerca de herança inclusiva em CESCHIM; GANIKO-DUTRA, 2020).

Para a adequada aprendizagem deste fenótipo, o Ensino de Biologia necessita superar as explicações lineares que o modelam. A superação destas distorções conceituais pode acontecer por meio do ensino de propriedades emergentes conforme proposto por Cooper (2016) para seleção natural (confira discussão acerca de seleção natural como propriedade emergente em GANIKO-DUTRA; CESCHIM; CALDEIRA, 2020), bem como por ensino integrado que supere fragmentações disciplinares.

Além desta característica que simplifica a emergência dos fenômenos biológicos, será discutida como a dicotomização fragiliza a complexidade e a diversidade da vida.

\section{Dicotomização (objeto)}

O conhecimento biológico em diversos aspectos possui conceitos dicotômicos, como por exemplo vivo/não vivo, sexuado/assexuado e ancestral/derivado. Destas dicotomias, decorrem alguns obstáculos a serem superados, pois quando um estudante se depara com um elemento que não se encaixa em um dos extremos, há dificuldade para explicar tal fenômeno. Por exemplo, a questão de o vírus ser ou não um ser vivo pode levantar um debate e desafiar o estudante a encaixá-lo no polo 'vivo' ou no polo 'não vivo' que estão estruturados no seu pensamento. A natureza do pensamento humano tem dificuldade em criar um terceiro, quarto ou quinto conceito no qual o vírus possa se encaixar, ou até mesmo lidar com o fato de que talvez ele não se encaixe em nenhum.

Um exemplo de dicotomia que organiza o pensamento humano pode ser constatado na forma como concebemos a reprodução sexuada. A origem de novos organismos por meio dessa forma de reprodução requer a fusão de dois gametas. Em animais, o número de gametas necessários para a formação do zigoto coincide com o número de tipos de 
gametas ou sexos biológicos, ou seja, são necessários dois gametas: um masculino e um feminino. Entretanto, esta forma de pensamento dicotômico a respeito da reprodução não pode ser extrapolada para todas as formas de vida. Em fungos do grupo Dikarya (Ascomycota e Basidiomycota) que realizam reprodução sexuada, ao contrário dos animais, não há diferença sexual morfológica. A diferença sexual, ou "tipos de acasalamento" (mating types), é determinada por diferenças nas sequências genéticas dos cromossomos sexuais. Assim, as hifas realizam cariogamia (fusão do material genético) apenas com outras hifas geneticamente distintas. Como não há diferenças sexuais morfológicas, os micélios não são denominados como macho ou fêmea, mas como '+' e '-' ou 'A' e 'a', por exemplo (BROWN; CASSELTON, 2001). Na espécie Coprinus cinereus existem dois loci que determinam as diferenças sexuais, denominados 'A' e 'B'. Para que a reprodução ocorra, é preciso que cada um dos parceiros sexuais apresente sequências genéticas diferentes em ambos loci. Estes genes são multialélicos: existem diversas variações de 'A' e de 'B'. Como a diferença sexual em fungos é dada por diferenças genéticas, o número de combinações possíveis de alelos equivale ao número de sexos, ou tipos de acasalamento. Desta forma, podemos dizer que nesta espécie existem mais de 12.000 sexos possíveis (RAPER, 1966). Este exemplo indica como o pensamento dicotômico pode ser um obstáculo para a aprendizagem a respeito da reprodução sexuada em fungos.

Outra característica frequentemente apresentada de forma dicotômica trata-se da frequência ou ausência dos dentes terceiros molares em seres humanos. Apesar de nem todos os indivíduos exibirem tal característica, em nossa espécie, o mais frequente é a ocorrência de quatro dentes terceiros molares conforme o indivíduo aproxima-se da idade adulta. Entretanto, não se trata de uma dualidade entre a ocorrência dos quatro dentes, ou ausência total dessas estruturas. Trata-se de um gradiente do número de dentes presentes na população: existem pessoas que apresentam nenhum, apenas um, dois, três ou os quatro dentes (FONSECA et al., 2018). Dessa forma, oferecemos outro exemplo de como a dicotomia pode gerar distorção conceitual acerca da variabilidade para um dado fenótipo.

A dicotomização decorrente da Distorção conceitual por antítese foi evidenciada no GPEB como uma etapa posterior à superação do adaptacionismo. Após diversas discussões que desafiavam a aplicação de modelos hipotéticos de seleção natural sem qualquer validação empírica, como o estudo da teoria quase neutra da evolução molecular (KREITMAN, 1996), os estudantes foram capazes de sugerir que as mudanças nas frequências fenotípicas podem ocorrer por deriva genética, polarizando as explicações para mudanças nas estruturas populacionais entre seleção natural e deriva genética.

Entretanto, uma vez que a Biologia é uma ciência complexa, ou seja, cujos fenômenos apresentam elevado número de unidades estruturais e processuais, o pensamento não deve ser estruturado por meio de antítese, mas por meio de gradientes ou pluralidade de explicações. Em relação às distorções que polarizam os fenótipos entre adaptados e não adaptados, conforme discutido anteriormente, a superação pode se dar por meio da apresentação de exemplos de seleção natural em que não existam apenas duas variedades de um traço, mas três ou mais, em que elas estejam organizadas em um gradiente de acordo com o fitness. 


\section{Cartesianismo}

Vamos considerar que podemos escrever sobre diferentes categorias ontológicas: (a) Coisas (substantivos); (b) Processos (verbos), que tem dimensão temporal; e (c) Estados, que tem dimensão atemporal (adjetivos, advérbios, afixos, as formas verbais de gerúndio, particípio e infinitivo e outras classes de palavras) (EVANS; GREEN, 2006).

Os fenômenos biológicos, devido ao funcionamento sensorial humano, podem equivocadamente ser representados mentalmente exteriorizados por meio da linguagem como se fossem Estados e não Processos. Fazendo uma analogia: um vídeo se torna reduzido a uma fotografia, pois um único aspecto ganha destaque em detrimento de uma história ontogenética mais ampla.

Podemos considerar exemplos de espécies simbiontes humanas, como Candida albicans ou Escherichia coli. Tradicionalmente classificadas como espécies comensais/ mutualísticas, ambas têm a capacidade de concretizar patologias, que inviabilizariam as classificações citadas. Passariam, deste modo, a ser considerados parasitos internos. Ou seja, as interações interespecíficas não podem ser restritas a categorias isoladas e distintas, pois as associações fazem parte de um amplo continuum em que é difícil saber onde um tipo de associação termina e a outra começa (PARMENTIER; MICHEL, 2013). Além disso, muitos organismos participarão de diferentes situações durante seu ciclo de vida e as definições podem representar apenas um momento pontual do passado.

No GPEB, a pesquisadora Maricato (2012) constatou que professores de Biologia em formação concebem as interações simbióticas (parasitismo, comensalismo e mutualismo) e as não simbióticas (como predação, amensalismo e competição) de modo estático e isolado. Os sujeitos de pesquisa recorriam às palavras que rotulam as categorias de interações interespecíficas, suprimindo qualquer análise da complexidade envolvida. Nos trechos abaixo, constam falas transcritas nas quais os estudantes indicam definições tradicionais de interações ecológicas para solucionar perguntas das discussões no GPEB (ver mais em MARICATO, 2012):

A2: Eu acho que quando fala de um parasita ... se ele se alimenta do sangue, ele é um parasita.

A1: Mas ele não vive às nossas custas.

A2: Ah! Mas ele usa o nosso sangue para se alimentar... sei lá. Eu vejo assim. Porque ele não é um predador. Ele é um parasita porque quando ele precisa ele pica e quando não precisa, não.

A3: Eu acho que ele é um predador para mim.

Podemos considerar que ocorre categorização analítico-cartesiana de tempo/ espaço referente aos processos biológicos nos casos supracitados, porque os diferentes tempos e espaços são compartimentalizados e desmembrados do todo, causando visões simplificadas/distorcidas das interações biológicas. Para a superação destas distorções, o pensamento necessita estruturar-se de modo sistêmico, ou seja, conceber as unidades que compõem as estruturas e processos biológicos de forma intrincada.

Em outras palavras, a forma de pensamento cartesiana categoriza as interações biológicas como Estados, eliminando a dimensão temporal e sistêmica desses fenômenos. Para a superação dessas distorções conceituais, recomendamos que os docentes ensinem que, ao longo de suas histórias de vida, os organismos estabelecem diversas interações com outras formas de vida, e que tais interações não são estáticas. Assim, em um dado momento, 
uma relação que poderia ser categorizada como comensalismo, por exemplo, em um diferente tempo e contexto, pode adquirir o estado de parasitismo. Dessa forma, encorajamos os professores de Biologia a evitarem o ensino de fenômenos de forma cartesiana, ou seja, de forma atemporal e fixa, concebendo-os como Estados, e encorajamos o ensino desses conceitos de forma sistêmica e integrada, contextualizados em uma dimensão temporal, concebendo-os como Processos, que são mutáveis ao longo da vida dos organismos.

\section{Teleologia}

A explicação causal teleológica na Biologia tende a ser problemática quando se trata de porquês evolutivos (ver mais acerca dessa discussão em CALDEIRA; CESCHIM; OLIVEIRA, 2018; CESCHIM, 2017). A teleologia configura uma forma intuitiva de entendimento, devido à estreita associação com explicações intencionais de comportamento proposital (LOMBROZO, 2006), que consiste em generalizar a ideia da criação de artefatos por organismos pensantes (os humanos) de forma inadequada. Ou seja, como o ser humano é muito bem sucedido como um designer inteligente, tem dificuldades para entender a origem de elementos do mundo que não tenham um planejamento. A seguir, serão fornecidos exemplos de falas nas quais sujeitos de pesquisa do GPEB exibiram discursos teleológicos para expressar conhecimento acerca de Biologia evolutiva.

\section{Reação com finalidade}

Para tratar desse tópico, podemos retomar o exemplo da jararaca ilhoa. Quando o sujeito diz que "A2: a jararaca da ilha, devido ao seu habitat e seu tipo de alimentação, se adaptou, desenvolveu um veneno mais potente para conseguir se alimentar de aves, o que não acontece com as jararacas de fora da ilha", o professor precisa de uma atitude atenta, pois pode se tratar de um 'atalho' da linguagem ou pode se tratar de uma externalização fidedigna do que o estudante está pensando. Uma possível estratégia é que o professor faça perguntas, como: "Com isso, você quer dizer que a jararaca precisou do veneno rápido então por isso conseguiu? Ou seja, a necessidade do veneno foi a causa de seu aparecimento?". Esse tipo de pergunta auxilia o estudante na dimensão metacognitiva, porque ele terá que concordar ou discordar do professor, analisando o próprio pensamento. Se o estudante concorda, trata-se de um pensamento teleológico que concebe mudanças evolutivas de seres vivos como reações ativas com finalidades. Se ele corrige utilizando corretamente uma terminologia seletiva, tratava-se apenas de uma simplificação do pensamento em uma linguagem mais descuidada.

\section{Natureza onisciente: antevisão}

Observamos no GPEB que professores de Biologia em formação tratam o processo evolutivo como uma entidade onisciente:

A4: eu acho que a natureza tem bastante disso de é melhor sobrar do que faltar [Referindo-se à flor com pólen desnecessário porque realiza partenogênese].

A2: mas a natureza, é óbvio que ela vai preferir que tenha mais fêmeas do que mais machos porque um macho pode copular várias fêmeas. 
Nos excertos acima (CESCHIM, 2017), o processo evolutivo foi referido como se fosse uma entidade consciente, capaz de fazer planos ou ter metas de longo prazo. A mediação didática dessa distorção requer metacognição para auxiliar o estudante a identificar que não há meios (mecanismos) biológicos que viabilizem tais ideias.

\section{Propósito ou progresso}

Os exemplos de falas transcritas abaixo (CESCHIM, 2017) contém casos nos quais os professores de Biologia em formação atribuem ao processo evolutivo uma conotação de progresso, ou seja, haveria um estado final ou propósito a ser atingido pela evolução.

A4: sempre que se fala em evolução, me vem à cabeça melhoramento.

A1: acho que vai passando por toda a complexidade desde os mais simples até os mais complexos. [a aluna tenta definir a evolução por meio de tal consideração].

Outras pesquisas também constataram professores de Biologia em formação e professores de Biologia atuantes que atribuem a ideia de progresso à evolução biológica (ver MEGLHIORATTI; CALDEIRA; BORTOLOZZI, 200; OLIVEIRA, 2015). A mediação didática dessa distorção requer, por exemplo, o apontamento de exemplos de organismos mais derivados na história evolutiva que tenham se tornado menos complexos estruturalmente.

Ao discutir o conceito de complexidade ao nível morfológico nos organismos, McShea (1991) oferece uma definição deste termo como uma propriedade estrutural que depende do número de diferentes partes de um sistema, bem como de seu arranjo. A complexidade pode ser medida a partir da análise das diferenças em uma série de elementos homólogos (MCSHEA, 1991). Por meio dessa abordagem, o autor constata que mamíferos aquáticos (organismos mais derivados), quando comparados com mamíferos terrestres dos quais são descendentes, sofreram perda de complexidade na coluna vertebral. No ambiente terrestre, os organismos sofrem a força da gravidade de forma mais intensa quando comparado ao meio aquático. A ausência dessa força como um fator do ambiente que causa uma diferença na taxa de sobrevivência e reprodução dos organismos na água, permitiu que organismos com uma coluna vertebral pouco complexa e diferenciada continuassem sobrevivendo e reproduzindo-se nesse ambiente (MCSHEA, 1991).

Por meio deste exemplo, é possível evidenciar que nem sempre organismos derivados são mais complexos. Acrescenta-se que para a adequada compreensão do conhecimento biológico, o pensamento humano precisa estruturar-se de forma contingente, superando a espontaneidade da teleologia (confira discussão acerca da natureza contingente da evolução em CESCHIM; CALDEIRA, 2020b). Para consultar uma estratégia didática de enfrentamento do problema do pensamento teleológico na interpretação da evolução biológica, ver Ceschim e Caldeira (2019).

\section{Aplicação do conhecimento biológico}

Em nosso Quadro 1, fizemos a explanação de algumas questões referentes à linguagem que causam distorções conceituais (Polissemia, Metáfora, Metonímia, Antítese e Personificação) e fizemos a exploração de aspectos espontâneos da cognição humana que dificultam conceber a natureza do conhecimento biológico (Causação linear, Dicotomização, 
Cartesianismo, Teleologia). Os aspectos linguísticos e os aspectos cognitivos estão intimamente relacionados, assim como os aspectos epistemológicos que serão tratados agora.

Os aspectos epistemológicos considerados são algumas formas de pensar próprias da Biologia que foram constatadas com distorções ao longo das pesquisas, cuja categorização no Quadro 1 consta como "Aplicação do conhecimento biológico" e os itens são: Desvinculação da representação com o fenômeno em si, Segmentação conceitual, e Desvio de nível hierárquico de organização biológica (conforme discutido anteriormente no item Linguagem).

Na formação inicial dos alunos, mediante o ensino em disciplinas que preconizam o ensino conceitual estanque e cartesiano - nas quais as subáreas biológicas não são tratadas como interdependentes - resulta frequentemente em um aprendizado por memorização. Para vencer as avaliações, segundo Caldeira (2009), os alunos tendem a se apropriar do conhecimento biológico por meio da repetição, de maneira mecânica e dogmática. Segundo a autora, os estudantes não conseguem fazer leitura de mundo por meio do conhecimento científico, assim, os graduandos tendem a perpetuar as próprias opiniões e visões.

Devido à profusão de conteúdo a ser ensinado em cada semestre, é comum aulas com muitos slides e com uma densidade de conteúdo abstrato em apenas quatro horas. Porém, como pontua Vygotsky (2000), a fraqueza da aprendizagem do saber científico está na concretude, pois está muito voltado para o verbalismo. Tendo em vista tal dificuldade, os conceitos científicos, além de serem definidos e explicados em um nível verbal de emprego de palavras para expressão de sua compreensão precisam extrapolar o nível da abstração. É preciso que haja aplicações a exemplos concretos específicos, pois nesta operação de aplicação/generalização de conceitos para exemplos específicos, o pensamento do estudante se torna mais concreto (move-se do abstrato ao fenômeno representado por palavras ou símbolos). De modo contrário, ou seja, em sentido inverso, os conceitos espontâneos que se desenvolveram fora de um sistema definido precisam ser articulados ao que se aprende nos sistemas de ensino. Os exemplos específicos do cotidiano precisam ser dirigidos à abstração e generalização. Os conceitos cotidianos passam a fazer parte de um sistema de relações e o objeto/fenômeno experienciado passa a compor um sistema científico.

Para Howe (1996), a aplicação de conceitos científicos de situações da vida real e a incorporação da experiência real a quadros conceituais científicos defendidas por Vygotsky são necessárias para evitar que o conceito aprendido no contexto científico permaneça um verbalismo ao invés de se tornar um verdadeiro conceito. Para se tornar conceito verdadeiro, requer ser aplicado a situações ou fenômenos encontrados por estudantes em suas vidas diárias.

Além da leitura de mundo ser dificultada por um currículo altamente segmentado por um formato disciplinar, também há consequências para as diferentes atuações que se espera que o profissional bacharel ou licenciado terá. O desempenho do egresso ao aplicar conhecimento para fazer transferência/generalização de seus saberes para novos exemplos ou para utilizar a criatividade para elaborar projetos/pesquisas poderá ser comprometido se ele estiver restrito à capacidade de fazer análises. Para promover a capacidade de fazer transferências, generalizações e para aumentar a criatividade, é necessário que o estudante também seja capaz de fazer sínteses.

Como fora defendido por Fauconnier e Turner (1998), o processo criativo depende de inputs independentes, que sofrem uma fusão e resultam em um terceiro item, o blending, 
ou criação. Ou seja, o processo criativo, embora imprevisível, ocorre quando inferências, emoções e eventos que não residem em nenhum dos input ou fontes passam a existir em uma terceira dimensão mista, que o espaço mental construído, criativo. Se a base da criatividade está em conectar itens uns nos outros, a disciplinaridade curricular dos cursos de Biologia permanecerá dificultando processos de criatividade da atuação dos estudantes e dos egressos.

As distorções conceituais descritas podem impedir que o pesquisador estruture seu pensamento a partir da epistemologia do conhecimento biológico, ou seja, de forma complexa, sistêmica e emergente. Tal impedimento pode comprometer a criatividade em propor soluções em perguntas de pesquisa, limitando respostas, e consequentemente o avanço do conhecimento científico. Tendo em vista que tal conhecimento pode prever o comportamento de determinados sistemas a partir do conhecimento de determinadas variáveis, um arcabouço pluralista de teorias refina a previsão que a humanidade pode estabelecer em um cenário de mudanças climáticas, ou de intervenção humana severa em determinado ambiente, por exemplo, o que pode culminar impactando a formulação de políticas públicas. Estas teorias enriquecem o potencial para a formulação de perguntas de pesquisa, justificando a necessidade da complexidade na formação de pesquisadores.

\section{Conclusões}

O trabalho realizado de análise e síntese das distorções conceituais encontradas em alunos em formação inicial de professores nos permite concluir que quando a construção de narrativas que articulem linguagem científica, pensamento biológico e aplicação do conhecimento não são privilegiadas, fatalmente haverá consequências na ação didática de futuros professores e na atuação de futuros bacharéis.

Constatamos nas pesquisas realizadas no GPEB, que a polissemia e figuras de linguagem que estruturam o pensamento humano (como metáfora, metonímia, antítese e personificação) têm estimulado a ocorrência de ruídos de comunicação, que podem ser causadores de distorções conceituais. Podemos concluir que os estudantes extraem significados não desejáveis das mensagens emitidas pelo discurso didático, produzindo conclusões próprias, conforme o conhecimento enciclopédico que possuem.

Após a análise das distorções conceituais, é possível sintetizar aspectos espontâneos do pensamento humano estruturados pela polissemia e pelas figuras de linguagem que se opõem a aspectos da Epistemologia da Biologia: o pensamento teleológico opõe-se ao pensamento contingente, a atribuição de causação linearopõe-se ao pensamento emergente, o pensamento cartesiano opõe-se ao pensamento sistêmico e o pensamento dicotômico opõe-se ao pensamento complexo. Considerando a articulação entre pensamento e linguagem, podemos concluir que a espontaneidade do pensamento humano se torna um dificultador da aprendizagem de Biologia se o discurso didático for impreciso, prejudicando a futura ação didática e epistemológica do formando.

Para evitar tais efeitos indesejáveis, além dos cuidados referentes à relação pensamento-linguagem, o ensino de aspectos da Epistemologia da Biologia precisa estar presente de forma explícita na formação inicial. É preciso ir além de ensinar Biologia: também é preciso ensinar sobre Biologia. Em relação às estratégias a serem adotadas no Ensino de Biologia para superação dos obstáculos epistemológicos citados, recomendamos a leitura de Caldeira (2020) e Senna, Ceschim e Ganiko-Dutra (2020). 
Em síntese, apontamos algumas estratégias que podem ser adotadas:

a. Diferenciar polissemias envolvidas no uso de termos científicos, detalhando como os frames se distinguem, para permitir um uso preciso de cada significado.

b. Destacar similaridades e incompatibilidades entre um conceito alvo e um conceito fonte no uso de metáforas, para que propriedades do conceito fonte não sejam atribuídas equivocadamente ao conceito alvo.

c. Evitar o uso de metonímia ao construir frases, para evitar o desvio de nível hierárquico biológico.

d. Incluir elementos mais numerosos e plurais, que sejam mais complexos que uma dicotomia ou um pensamento dividido por uma antítese, para evitar a simplificação de processos e de objetos que são compostos por um conjunto maior que duas variáveis.

e. Evitar a personificação na estrutura das frases, para que não se atribua caráter volitivo a seres vivos não dotados de capacidade teleológica intencional.

f. Conceituar propriedades emergentes e integrar disciplinas biológicas, para que seja possível a identificação das conexões e das interdependências dos diferentes níveis de organização biológica.

g. Apontar exemplos de organismos derivados que tenham se tornado menos complexos para indicar que o processo evolutivo não tem uma tendência obrigatória ao aumento de complexidade.

h. Descrever o pensamento contingente, diferenciando-o da teleologia, para que a evolução seja caracterizada como contingente.

i. Aplicar as teorizações e abstrações do conteúdo universitário para leituras de mundo, traduzindo para as palavras cotidianas e exemplos concretos, para que a mediação didática não se restrinja a um verbalismo.

j. Além de fazer análises, explorando cada fase de um processo ou cada elemento de uma estrutura, também fazer sínteses, para que se produza uma visão de todo, que integre o saber de modo a construir articulações epistemológicas.

Trata-se de demandas de caráter prático para o currículo de formação inicial, que podem ser inseridas em disciplinas pré-existentes ou novas. Os graduandos podem ter situações de aplicações nas quais possam experienciar os objetivos acima, para que possam se apropriar de tais estratégias.

Acrescente-se que se trata de um campo fértil de investigação da relação pensamentolinguagem, pois os critérios para qualificar distorções conceituais em Biologia aqui propostos foram construídos a partir de um arcabouço de pesquisas empíricas gerando a possibilidade de ser generalizável em outras pesquisas, contribuindo para o Ensino de Biologia.

\section{Referências}

ANDRADE, M. A. B. S. A epistemologia da biologia na formação de pesquisadores: compreensão sistêmica de fenômenos moleculares. 2011. Tese (Doutorado em Educação para a Ciência) Faculdade de Ciências, Universidade Estadual Paulista, Bauru, 2011. Disponívelem: https:// repositorio.unesp.br/handle/11449/102025. Acesso em: 20 out. 2020.

BRANDO, F. R. Proposta didática para o ensino médio de biologia: as relações ecológicas no cerrado. 2010. Tese (Doutorado em Educação para a Ciência) - Faculdade de Ciências, Universidade Estadual Paulista, Bauru, 2010. Disponívelem: https://repositorio.unesp.br/handle/11449/102036. Acesso em: 20 out. 2020. 
BROWN, A. J.; CASSELTON, L. A. Mating in mushrooms: increasing the chances but prolonging the affair. Trends in Genetics, Cambridge, v. 17, n. 7, p. 393-400, 2001.

CALDEIRA, A. M. A. (org.). Didática e epistemologia da biologia. São Paulo: Cultura Acadêmica, 2020.

CALDEIRA, A. M. A. A relação pensamento e linguagem: formação de conceitos científicos em ciências naturais. In: CALDEIRA, A. M. A.; ARAÚJO, E. S. N. N. (org.). Introdução à didática da biologia. São Paulo: Escrituras, 2009. p. 157-172.

CALDEIRA, A. M. A.; CESCHIM, B.; OLIVEIRA, T. B. Formação inicial de professores de ciências biológicas: dificuldades de compreensão do tema evolução biológica. In: ZULIANI, S. R. Q. A.; TEZANI, T. C. R.; CAPELLINI, V. L. M. F. (org.). Cadernos de docência na educação básica VI: relação teoria e prática: contribuições para a educação básica. São Paulo: Cultura Acadêmica, 2018. p. 148160.

CAPONI, G. Função e desenho na biologia contemporânea. São Paulo: Associação Filosófica Scientiae Studia, 2012.

CESCHIM, B. O emprego da teleologia na interpretação da biologia funcional e evolutiva: um estudo a respeito de concepções e da evolução conceitual de alunos de licenciatura em ciências biológicas. 2017. Dissertação (Mestrado em Educação para a Ciência) - Faculdade de Ciências, Universidade Estadual Paulista, Bauru, 2017.

CESCHIM, B.; CALDEIRA, A. M. A. A dominância está nos olhos de quem vê: a fisiologia que explica fenótipos dominantes e recessivos. In: CALDEIRA, A. M. A. (org.). Didática e epistemologia da biologia. São Paulo: Cultura Acadêmica, 2020a. p. 87-124.

CESCHIM, B.; CALDEIRA, A. M. A. É caminhando que se faz o caminho: a natureza contingente da evolução como objeto de ensino. In: CALDEIRA, A. M. A. (org.). Didática e epistemologia da biologia. São Paulo: Cultura Acadêmica, 2020b. p. 17-52.

CESCHIM, B.; CALDEIRA, A. M. A. Pedagogical strategies for the problem of teleology in the teaching of biological evolution. In: OLIVEIRA, A. W.; COOK, K. L. (ed.). Evolution education and the rise of the creationist movement in Brazil. London: Lexington Books, 2019. p. 111-126.

CESCHIM, B.; GANIKO-DUTRA, M. "Genético" e "hereditário": como a biologia contemporânea explica essa relação? In: CALDEIRA, A. M. A. Didática e epistemologia da biologia. São Paulo: Cultura Acadêmica, 2020. p. 169-202.

COOPER, R. A. Natural selection as an emergent process: instructional implications. Journal of Biological Education, London, v. 51, n. 3, p. 247-260, 2016. DOI: https://doi.org/gg2czt.

CRUSE, D. A. Meaning in language: an introduction to semantics and pragmatics. New York: Oxford Linguistics, 2011.

ELBOW, P. The uses of binary thinking. Journal of Advanced Composition, USA, v. 13, n. 1, p. 51-78, 1993.

EVANS, V.; GREEN, M. Cognitive linguistics: an introduction. New York: Routledge, 2006.

EVERT, R. F.; EICHHORN, S. E. Raven: biologia vegetal. 8. ed. Rio de Janeiro: Guanabara Koogan, 2014.

FAUCONNIER, G.; TURNER, M. Conceptual integration networks. Cognitive Science, USA, v. 22, n. 2, p. 133-187, 1998.

FILLMORE, C. J. Frame semantics. In: GEERAERTS, D. (ed.). Cognitive linguistics: basic readings. Berlin: Mouton de Gruyter, 2006. p. 373-400.

FISHER, K.; WANDERSEE, J. H.; MOODY, D. E. Mapping biology knowledge. Dordrecht: Springer, 2001. 
FONSECA, A. L. F. B.; MARQUES, F. L.; BRASILEIRO, C. B.; MILAGRES, R. M. C.; AMARAL, T. M. P. Estudo da frequência e da variabilidade de posições dos terceiros molares nas radiografias panorâmicas no serviço de radiologia da Faculdade de Odontologia da Universidade Federal de Minas Gerais. Arquivos em Odontologia, Belo Horizonte, v. 54, n. e01, p. 1-11, 2018.

GANIKO-DUTRA, M.; CESCHIM, B.; CALDEIRA, A. M. A. Nem só de seleção natural se constrói uma teoria evolutiva. In: CALDEIRA, A. M. A. (org.). Didática e epistemologia da biologia. São Paulo: Cultura Acadêmica, 2020. p. 53-86.

HACKER, P. M. S. Natureza humana: categorias fundamentais. Porto Alegre: Artmed, 2010.

HOWE, A. C. Development of science concepts within a vygotskian framework. Science Education, Hoboken, v. 80, n. 1, p. 35-51, 1996.

JUSTINA, L. A. D. Investigação sobre um grupo de pesquisa como espaço coletivo de formação inicial de professores e pesquisadores de biologia. 2011. Tese (Doutorado em Educação para a Ciência) Faculdade de Ciências, Universidade Estadual Paulista, Bauru, 2011.

KAŁUŻA, I. Antithesis: a linguistic approach. Kraków: Jagiellonian University, 1984.

KIERS, E. T.; WEST, S. A.; WYATT, G. A. K.; GARDNER, A.; BÜCKING, H.; WERNER, G. D. A. Misconceptions on the application of biological market theory to the mycorrhizal symbiosis. Nature Plants, London, v. 2, n. 16063 , p. 1, 2016.

KREITMAN, M. The neutral theory is dead: long live the neutral theory. Bioessays, Cambridge, v. 18, n. 8, p. 678-683, 1996.

LAKOFF, G.; JOHNSON, M. Metaphors we live by. Chicago: University of Chicago Press, 2008.

LANGACKER, R. W. Cognitive grammar. In: GEERAERTS, D. (ed.). Cognitive linguistics: basic readings. Berlin: Mouton de Gruyter, 2006. p. 29-68.

LOMBROZO, T.; CAREY, S. Functional explanation and the function of explanation. Cognition, Amsterdam, v. 99, n. 2, p. 167-204, 2006.

LOPES, S.; ROSSO, S. Bio. 3 ed. São Paulo: Saraiva, 2016. 3 v.

LUCAS, A. M. The teaching of "adaptation". Journal of Biological Education, New York, v. 5, n. 2, p. 8690, 1971.

MARICATO, F. E. A (re)construção coletiva do conceito de interação biológica: contribuição para a epistemologia da biologia e a formação de pesquisadores e professores. 2012. Tese (Doutorado em Educação para a Ciência) - Faculdade de Ciências, Universidade Estadual Paulista, Bauru, 2012.

MARTÍNEZ, N. M. Conocimientos que interaccionan en la enseñanza de las ciencias. Enseñanza de las Ciencias, Bracelona, v. 21, n. 1, p. 65-78, 2003.

MAYR, E. Biologia: ciência única. São Paulo: Companhia das Letras, 2005.

MCSHEA, D. W. Complexity and evolution: what everybody knows. Biology and Philosophy, Dordrecht, v. 6, p. 303-324, 1991.

MEGLHIORATTI, F. A. O conceito de organismo: uma introdução à epistemologia do conhecimento biológica na formação e graduandos de biologia. 2009. Tese (Doutorado em Educação para a Ciência) - Faculdade de Ciências, Universidade Estadual Paulista, Bauru, 2009.

MEGLHIORATTI, F. A.; CALDEIRA, A. M. A.; BORTOLOZZI, J. Recorrência da idéia de progresso na história do conceito de evolução biológica e nas concepções de professores de biologia: interfaces entre produção científica e contexto sócio-cultural. Filosofia e História da Biologia, São Paulo, v. 1, n. 1, p. 107-123, 2006. 
MENDEL, G. Experiments in plant hybridisation. New York: Cosimo Classics, 2008.

NÖE, R.; HAMMERSTEIN, P. Biological markets. Tree, USA, v. 10, n. 8, p. 336-339, 1995.

OGO, M. Y.; GODOY, L. P. \#Contato biologia, $3^{\circ}$ ano. São Paulo: Quinteto Editorial, 2016.

OLIVEIRA, T. B. Uma pesquisa didático-epistemológica na formação inicial em ciências biológicas: como a evolução forjou a grande quantidade de criaturas que habitam o nosso planeta? 2015. 209 f. Tese (Doutorado em Educação para a Ciência) - Faculdade de Ciências, Universidade Estadual Paulista, Bauru, 2015.

PARMENTIER, E.; MICHEL, L. Boundary lines in symbiosis forms. Symbiosis, Philadelphia, v. 60, n. 1, p. $1-5,2013$.

RAPER, J. R. Genetics of sexuality in higher fungi. New York: Ronald Press, 1966.

SENNA, K. N.; CESCHIM, B.; GANIKO-DUTRA, M. A organização do conteúdo biológico no processo de mediação didática. In: CALDEIRA, A. M. A. (org.). Didática e epistemologia da biologia. São Paulo: Cultura Acadêmica, 2020. p. 251-279.

VYGOTSKY, L. S. A construção do pensamento e da linguagem. São Paulo: Martins Fontes, 2000.

WYATT, G. A. K.; KIERS, E. T.; GARDNER, A.; WEST, S. A. A biological market analysis of the plantmycorrhizal symbiosis. Evolution, USA, v. 68, n. 9, p. 2603-2618, 2014. 